\title{
The potential of spring distraction to dynamically correct complex spinal deformities in the growing child
}

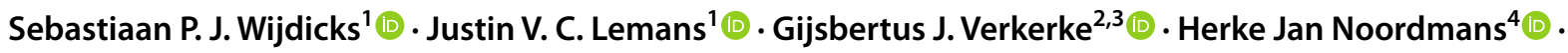 \\ René M. Castelein ${ }^{1}{ }^{1} \cdot$ Moyo C. Kruyt ${ }^{1}{ }^{1}$
}

Received: 16 June 2020 / Revised: 26 August 2020 / Accepted: 20 September 2020 / Published online: 6 October 2020

(c) The Author(s) 2020

\begin{abstract}
Purpose Current treatment of progressive early onset scoliosis involves growth-friendly instrumentation if conservative treatment fails. These implants guide growth by passive sliding or repeated lengthenings. None of these techniques provide dynamic correction after implantation. We developed the spring distraction system (SDS), by using one or multiple compressed springs positioned around a standard sliding rod, to provide active continuous distraction of the spine to stimulate growth and further correction. The purpose of this study was to determine feasibility and proof of concept of the SDS.

Methods We developed a versatile, dynamic spring distraction system for patients who would benefit from active continuous distraction. This prospective case series evaluates four patients with exceptional and progressive congenital spine deformities. Results Four patients had a mean age of 6.8 years at surgery with a mean follow-up of 36 months (range 25-45). The mean progressive thoracic lordosis, which was the reason for initiating surgical treatment in two patients, changed from $32^{\circ}$ lordosis preoperatively to $1^{\circ}$ kyphosis post-operatively. During follow-up, this further improved to $32^{\circ}$ thoracic kyphosis. In the two other patients, with cervicothorcacic scoliosis, the main coronal curve improved from $79^{\circ}$ pre-operatively to $56^{\circ}$ post-operatively and further improved to $42^{\circ}$. The mean T1-S1 spine growth during follow-up for all patients was $1.3 \mathrm{~cm} /$ year. There was one reoperation because of skin problems and no device-failures.

Conclusion These early results show the feasibility and the proof of concept of spring-based distraction as a dynamic growthenhancing system with the potential of further correction of the deformity after implantation.
\end{abstract}

Keywords Dynamic growth enhancing correction · Innovative device $\cdot$ Growing rods $\cdot$ Spring distraction · Early onset scoliosis

\author{
Moyo C. Kruyt \\ m.c.kruyt@umcutrecht.nl \\ Sebastiaan P. J. Wijdicks \\ s.p.j.wijdicks@umcutrecht.nl \\ Justin V. C. Lemans \\ j.v.c.lemans-3@umcutrecht.nl \\ Gijsbertus J. Verkerke \\ g.j.verkerke@gmail.com \\ Herke Jan Noordmans \\ h.j.noordmans@umcutrecht.nl \\ René M. Castelein \\ r.m.castelein@umcutrecht.nl
}

1 Department of Orthopaedic Surgery, University Medical Center Utrecht, Heidelberglaan 100, 3584 CX Utrecht, The Netherlands

2 Department of Biomechanical Engineering, University of Twente, Drienerlolaan 5, 7522 NB Enschede, The Netherlands

3 Department of Rehabilitation Medicine, University of Groningen, University Medical Center Groningen, Hanzeplein 1, 9713 GZ Groningen, The Netherlands

4 Department of Medical Technology and Clinical Physics, University Medical Center Utrecht, Heidelberglaan 100, 3584 CX Utrecht, The Netherlands 


\section{Introduction}

Early onset spinal deformities can progress severely during growth. Especially in young children, this may result in thoracic insufficiency syndrome or untreatable spinal malformations [1]. When casts or brace treatment cannot control progression, implantation with internal growth-friendly systems is indicated [2]. Current growth-friendly systems can potentially stop curve progression while allowing the spine to maintain growth [3]. Some of these implants guide the reduced deformity by passive sliding, e.g., Shilla or Luque trolley techniques $[4,5]$. More commonly, implants that follow growth with repeated lengthenings are used, e.g., traditional growing rods (TGR), vertical expandable prosthetic titanium rib (VEPTR) or magnetically controlled growing rods (MCGR) $[1,2,6]$. Although these techniques have dramatically improved our ability to treat early onset spinal deformities, some aspects can still be addressed to improve surgical outcomes: First, none of these systems dynamically stimulate growth and further reduction of the affected spinal segments. As a consequence, physiologic growth is not at all maintained [3]. Second, repeated anaesthesia and surgery, but also repeated outpatient visits and interventions have shown detrimental effects [7-9]. Third, due to the stiffness of current implant designs, the sagittal profile may be difficult to address, and autofusion often occurs, that potentially results in crankshafting and loss of spinal growth. Last, instrumentation failures are frequently observed [10,11].

We were confronted with patients for whom we felt that the existing systems, even with the shortest possible distraction intervals, would have resulted in autofusion over a short period of time and therefore would not be effective. For these patients we developed and applied the spring distraction system (SDS). It uses the continuous distraction force of a compressed spring that is positioned around a traditional growing rod $(4.5 \mathrm{~mm})$ that is allowed to slide on one end (Fig. 1). This paper reports on the first experience with SDS for the correction of severe spinal deformities.

\section{Material and methods}

\section{Study design}

Prospective case series of patients with progressive congenital spine deformities treated with the SDS. To prospectively investigate the SDS, institutional ethical review board approval was obtained (METC nr. 16-276).

\section{Design and investigational medical device dossier}

To our knowledge no papers exists that investigate spring distraction in human or animals. Therefore, we had to rely on other literature that investigated the forces that can be

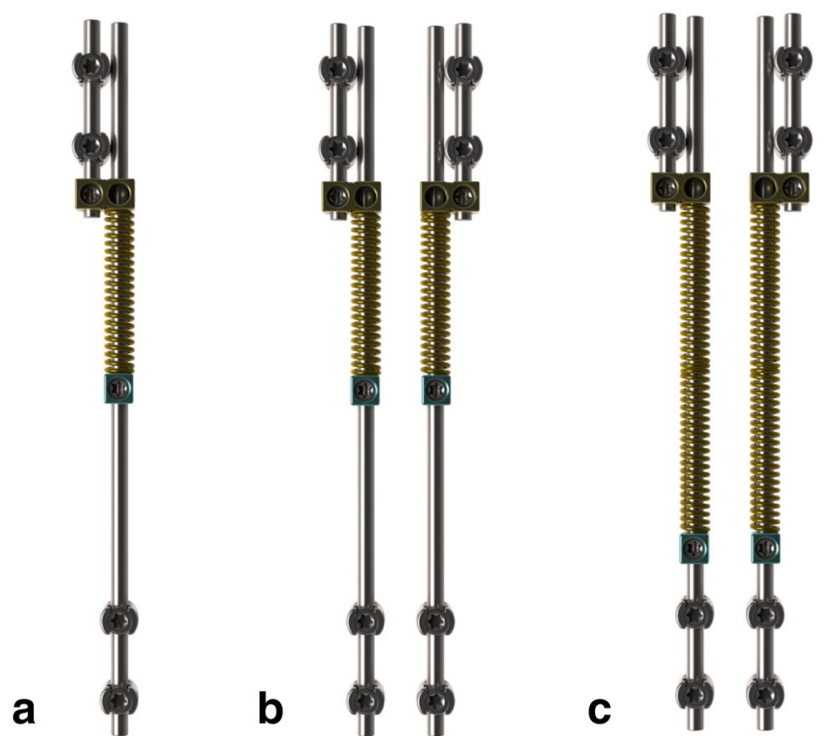

Fig. 1 Three configurations of the SDS consisting of a parallel connector (yellow) with an oversized medial 5.5 hole and lateral 4.5 hole, a $4.5 \mathrm{~mm}$ rod (silver) that can slide though the 5.5 hole of the parallel connector, a buttress (turquoise) used to tension or re-tension the spring and proximal and distal pedicle screws (silver): a single concave SDS b bilateral SDS and $\mathbf{c}$ bilateral SDS with two springs in series

tolerated by the growing spine otherwise. For that purpose, we performed an extensive literature review that involved distraction forces in clinical, cadaver and finite element models. This review yielded 1000 papers of which some were very relevant [12-22] and will be submitted separately. In addition, we measured the distraction forces that we applied during traditional growing rod lengthenings. Based on these studies and expert evaluation by the medical engineers of the UMC Utrecht and University of Twente we concluded that a distraction force between 50 and $100 \mathrm{~N}$ on each side of the spine should be safe.

Based on the specifications from this research a medical grade Titanium (Ti-6Al-4V) spring was designed and manufactured. The ISO 13,485 certified department of medical technology and physics of our hospital is competent to design and manufacture medical devices for custom use and clinical research in compliance with the European Medical Device regulations. During the design phase a risk analysis was performed through which Titanium (Ti-6Al-4 V) was chosen mainly because this material is mostly bioinert. The spring dimensions were chosen to fit around a standard $4.5 \mathrm{~mm}$ rod and to provide the predetermined distraction force over a specific distance. The following parameters were chosen for the spring: inner diameter of $5.16 \mathrm{~mm}$, outer diameter of $7.70 \mathrm{~mm}$, wire diameter of $1.27 \mathrm{~mm}$, free length of $72.0 \mathrm{~mm}$, compressed length of $38.0 \mathrm{~mm}$, spring constant of $2.15 \mathrm{~N} / \mathrm{mm}$ and maximum force of $75 \mathrm{~N}$. The spring was 
Fig. 2 5-year-old girl with SCT syndrome had Smith-Peterson osteotomies Th7-Th11 and placement of a bilateral SDS (the springs were re-tensioned after 19 months): a pre-operative $\mathbf{b}$ post-operative (c) at 19 months follow-up before retensioning (d) after re-tensioning and (e) at latest follow-up (3.9 years) frontal radiographs with corresponding sagittal radiographs $(\mathbf{f}-\mathbf{j})$. The major coronal curve changed from $84^{\circ}$ pre-operatively to $43^{\circ}$ postoperatively and to $54^{\circ}$ at latest follow-up. The thoracic lordosis of $43^{\circ}$ changed to a kyphosis of $0.1^{\circ}$ post-operatively to $43^{\circ}$ at latest follow-up
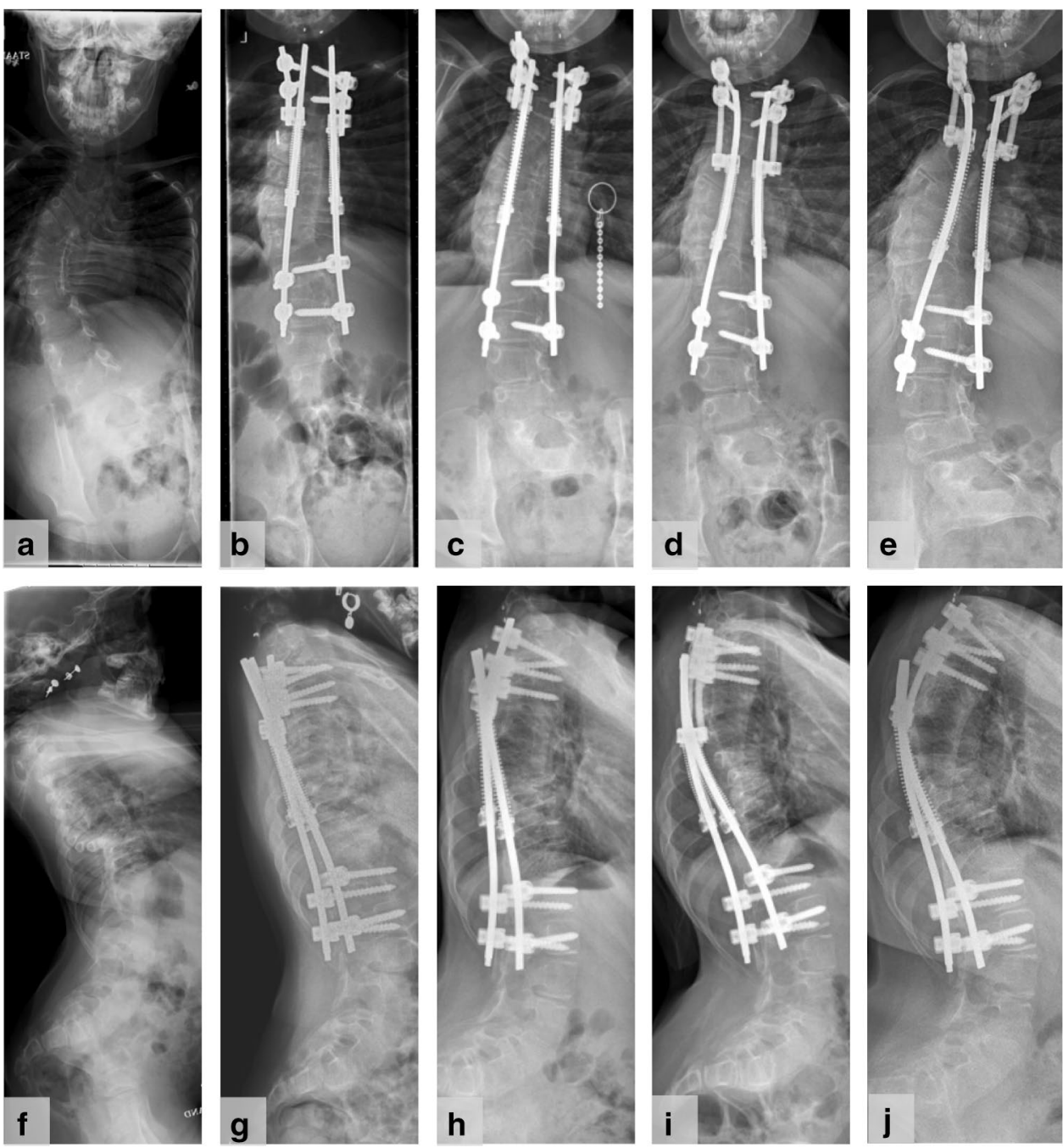

manufactured by Lesjöfors (Karlstad, Sweden). Lesjöfors acted only as the provider of the springs as it has a quality management system ISO 9001 for producing springs, but not a quality management system for producing medical devices (ISO 13,485), The ISO 13,485 certified medical technology and clinical physics department, thus acted as the manufacturer of the spring, took lead in the design and manufacturing process and created the investigational medical device dossier (IMDD), consisting of: a spring description (including spring manufacturing process, sample control report and material inspection certificates), device classification, essential requirement checklist, risk analysis, user manual, processes of quality control, post market surveillance and vigilance. The investigational medical device dossier (IMDD) was approved after review of the medical technology and physics department (Project number 150310) and approved by the institutional ethical review board (METC nr. 16-276).

\section{Surgical Techniques}

After informed consent, patients received the SDS as an adjunct to conventional, pedicle screw based growing rods. For the lordotic patients we did posterior releases with Smith-Petersen osteotomies. For the mainly scoliotic patients, this included a convex hemi-vertebrectomy and hemi-epiphysiodesis. The SDS involves a distraction spring, placed around a conventional $4.5 \mathrm{~mm}$ rod that is not fixed but which is allowed to glide through an oversized parallel connector at its proximal anchor (Fig. 1). A buttress that can be locked on the $4.5 \mathrm{~mm}$ rod is used to tension the spring. A single spring can provide a maximum force of $75 \mathrm{~N}$ and can lengthen $34 \mathrm{~mm}$. Implanting bilateral SDS springs doubles this force to $150 \mathrm{~N}$. Implanting two springs in series doubles the working length to $68 \mathrm{~mm}$ while keeping the force the same (Fig. 1). When the spring is fully distracted, the rod can still glide through the parallel connector and function as a gliding system. Alternatively, the spring can be re-tensioned by adjusting the buttress through a small 
Fig. 3 9-year-old girl with SCT syndrome had dorsal SmithPeterson osteotomies Th6-Th11 and placement of a bilateral SDS (the dual MCGR broke after 6 months): a pre-operative before MCGR surgery $\mathbf{b}$ post-operative (c) after broken MCGR and before bilateral SDS implantation d post-operative and (e) at latest follow-up (2.2 years) frontal radiographs with corresponding sagittal radiographs $(\mathbf{f}-\mathbf{j})$. The major coronal curve changed from $57^{\circ}$ pre-operatively to $58^{\circ}$ postoperatively and to $59^{\circ}$ at latest follow-up. The thoracic lordosis of $35^{\circ}$ changed to a kyphosis of $3^{\circ}$ post-operatively to $21^{\circ}$ at latest follow-up
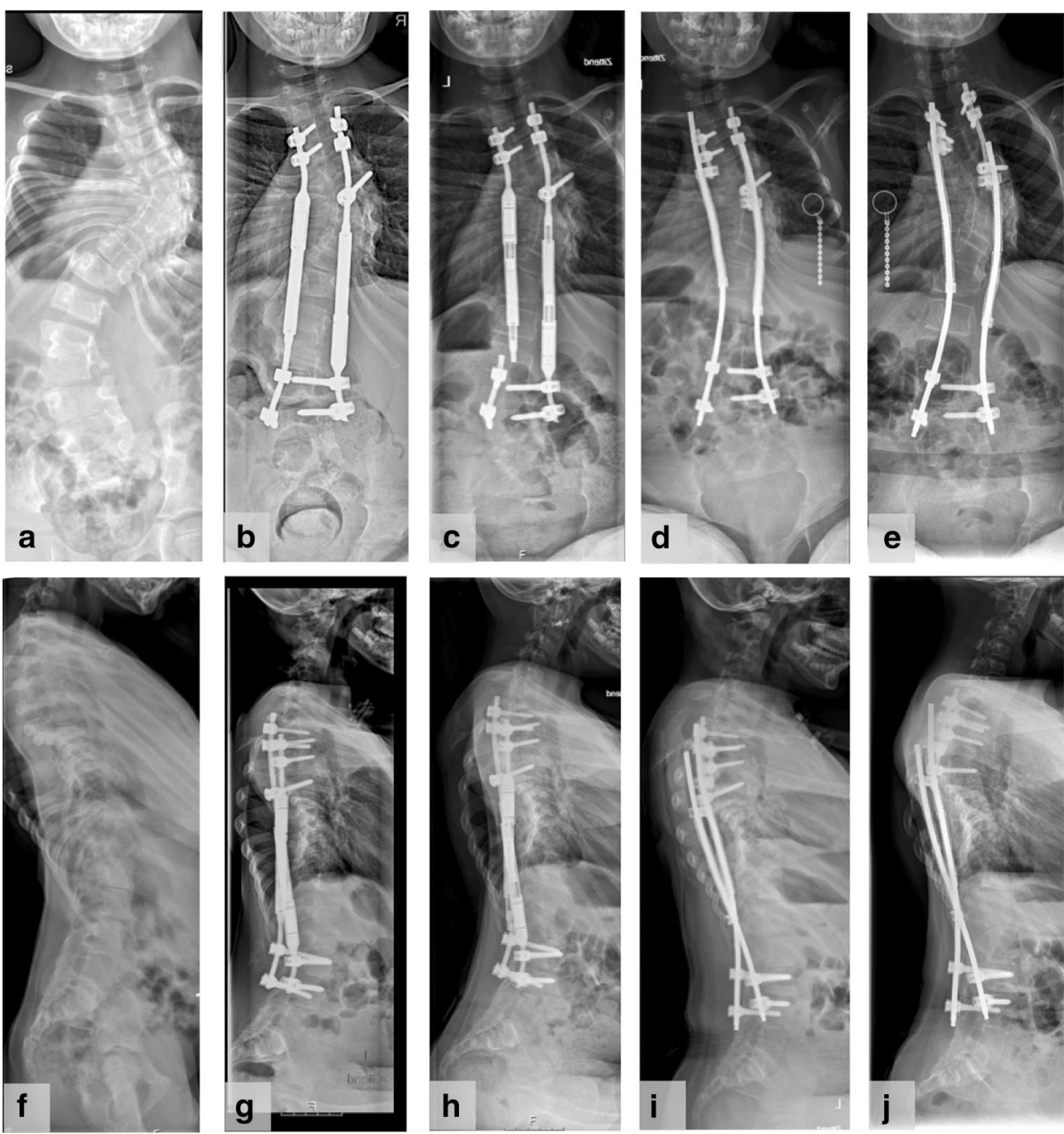

incision. The three configurations used in the 4 patients are shown in Fig. 1. After surgery the patients were allowed normal activities with the exception of contact sports. No braces were used.

\section{Patient cohort}

The first patient, operated in 2015, was a 5-year-old girl that suffered from a rare skeletal dysplasia, spondylocarpotarsal synostosis (SCT) syndrome. A key feature of this syndrome is failure of segmentation of the posterior elements of the spine. The continued anterior growth results in a rapidly progressive lordosis which caused thoracic insufficiency. Because we expected all currently available growthfriendly systems to fail for this specific case, we developed the posterior spring distraction system which we implanted bilaterally. Another girl with the same syndrome was first treated with bilateral MCGRs. Because the MCGRs could not reduce the deformity and fractured within 6 months, we decided to replace them with the SDS. Where the goal of treatment was primarily to create kyphosis for the SCT syndrome patients, a bilateral SDS was implanted. Because of the available space in the 2 nd patient, we decided to increase the working length by using two springs in series. This doubled the working length, while the force remains the same $(75 \mathrm{~N})$. This was considered an advantage as the first patient already had a fully distracted spring after two years. The two other patients had high thoracic and cervical congenital anomalies with severe and progressive scoliotic deformity. The main goal was to correct the coronal deformity and a single concave SDS was implanted with a contralateral instrumented hemi-epiphysiodesis with sliding rods. In these patients we opted for the SDS approach to prevent the extensive procedure of hemivertebral resection. If treatment would fail, in terms of dynamic correction, hemivertebral resection can still be performed during definitive fusion surgery. 

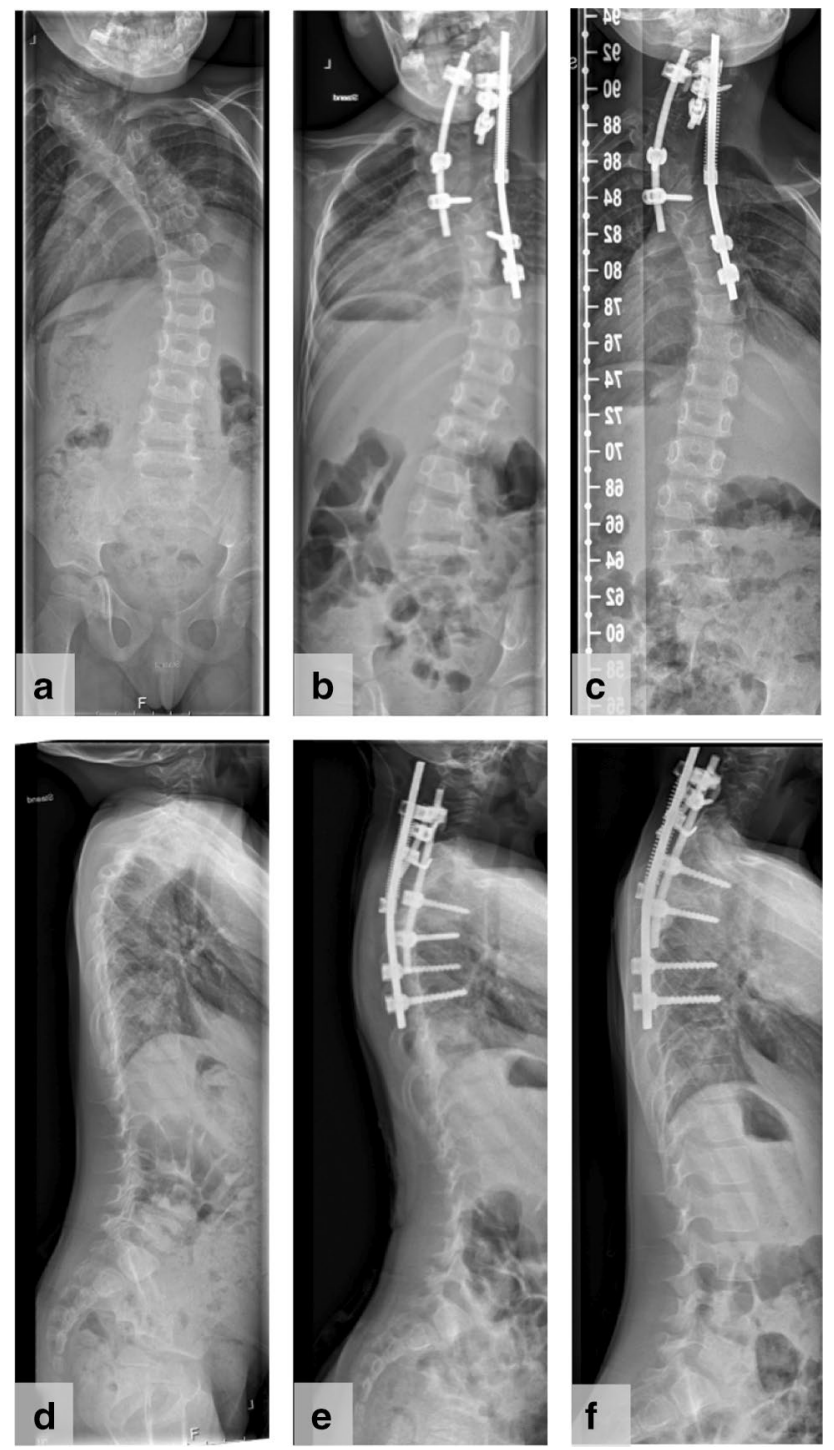

Fig. 4 3-year-old girl with high thoracic scoliosis and severe clinical torticollis had convex posterior hemivertebrectomy and hemiepiphysiodesis and a concave SDS: a pre-operative b post-operative and (c) at latest follow-up (2.1 years) frontal radiographs with corresponding sagittal radiographs $(\mathbf{d}-\mathbf{f})$. The major coronal curve changed from $87^{\circ}$ pre-operatively to $66^{\circ}$ post-operatively and to $50^{\circ}$ at latest follow-up

\section{Data collection}

Demographics, medical history, pre-, per- and post-operative clinical and radiographic parameters, as well as adverse events were prospectively recorded. Follow up was similar to TGR, with visits and radiographs at 1, 3 and 6 months and, if possible, every 6 months thereafter. Spinal lengths were measured after the $\mathrm{x}$-rays were calibrated with the external diameter of the spring $(7.70 \mathrm{~mm})$. For height measurements (T1-T12 and T1-S1), the perpendicular distance between horizontal lines through midpoints of the chosen vertebral endplates was measured on coronal x-rays. For freehand measurements, we measured the curved mid-spinal line T1-S1 on coronal and sagittal $\mathrm{x}$-rays. This freehand line, that is not affected by shape changes, was drawn through the exact midpoint of the upper and lower endplate of every vertebra [3]. Finally, the spring lengths on coronal and sagittal x-rays were measured on post-operative radiographs and at latest follow-up. The plane with the longest direct postoperative spring length was used for measuring spring length increase over time. All growth measurements were recorded from the first post-operative measurements to the latest follow-up measurements. To determine if further correction after surgery influenced spinopelvic balance, we measured apical vertebral translation, coronal balance, sagittal vertical axis (SVA) and pelvic obliquity. The measurements were performed with Surgimap Spine software (Nemaris Inc., New York, NY). All measurements were audited by an independent observer and discrepancies discussed until consensus was reached. Descriptive statistics were computed for the cohort, providing means and standard deviations.

\section{Results}

\section{Patient demographics}

All patients were referrals from other centers with already advanced deformities. The mean age at index surgery was 6.8 years $( \pm 2.8)$ years. All patients were female. The mean age of first radiographical diagnosis of the scoliosis was 2.5 $( \pm 2.2)$ years. The first patient was operated in 2015 and the mean follow-up time for all patients is $3.0( \pm 1.2)$ years. Mean overall surgery time for the procedures was $191 \mathrm{~min}$ (range: 130-305). The instrumented segment involved 12 (range: 10-14) vertebrae with the lower instrumented vertebra varying from T10-L3. No intra-operative neuro-monitoring issues or complications occurred. Mean admission time was 6 days (range: $5-10$ ). Mean estimated blood loss was $300 \mathrm{cc}$ (range: 250-415).

\section{Radiographic outcomes}

The mean thoracic lordosis of the two SCT-patients could be reduced from $-32^{\circ}$ (lordosis) pre-operative, to a $1^{\circ}$ kyphosis post-operative. During follow-up this dramatically improved further to a $32^{\circ}$ thoracic kyphosis, despite our expectations that the lamina would fuse again (Figs. 2 and 3). In the two mainly cervicothoracic scoliotic patients, the mean major curve reduced from $79^{\circ}$ to $56^{\circ}$ and further improved to $42^{\circ}$ (Fig. 4, Fig. 5 and Fig. 6). Apical vertebral translation improved from $45 \mathrm{~mm}$ pre-operative to $15 \mathrm{~mm}$ at latest follow-up. All (including individual) measurements are given in Tables 1, 2 and 3. 
Fig. 5 8-year-old girl with high thoracic scoliosis and severe clinical torticollis had a posterior convex hemiepiphysiodesis and a concave SDS: a pre-operative $\mathbf{b}$ post-operative and $(\mathbf{c})$ at 19 months follow-up before implant exchange (d) after implant exchange and (e) at latest follow-up (1.9 years) frontal radiographs with corresponding sagittal radiographs $(\mathbf{f}-\mathbf{j})$. The major coronal curve changed from $70^{\circ}$ pre-operatively $46^{\circ}$ post-operatively and to $34^{\circ}$ at latest follow-up
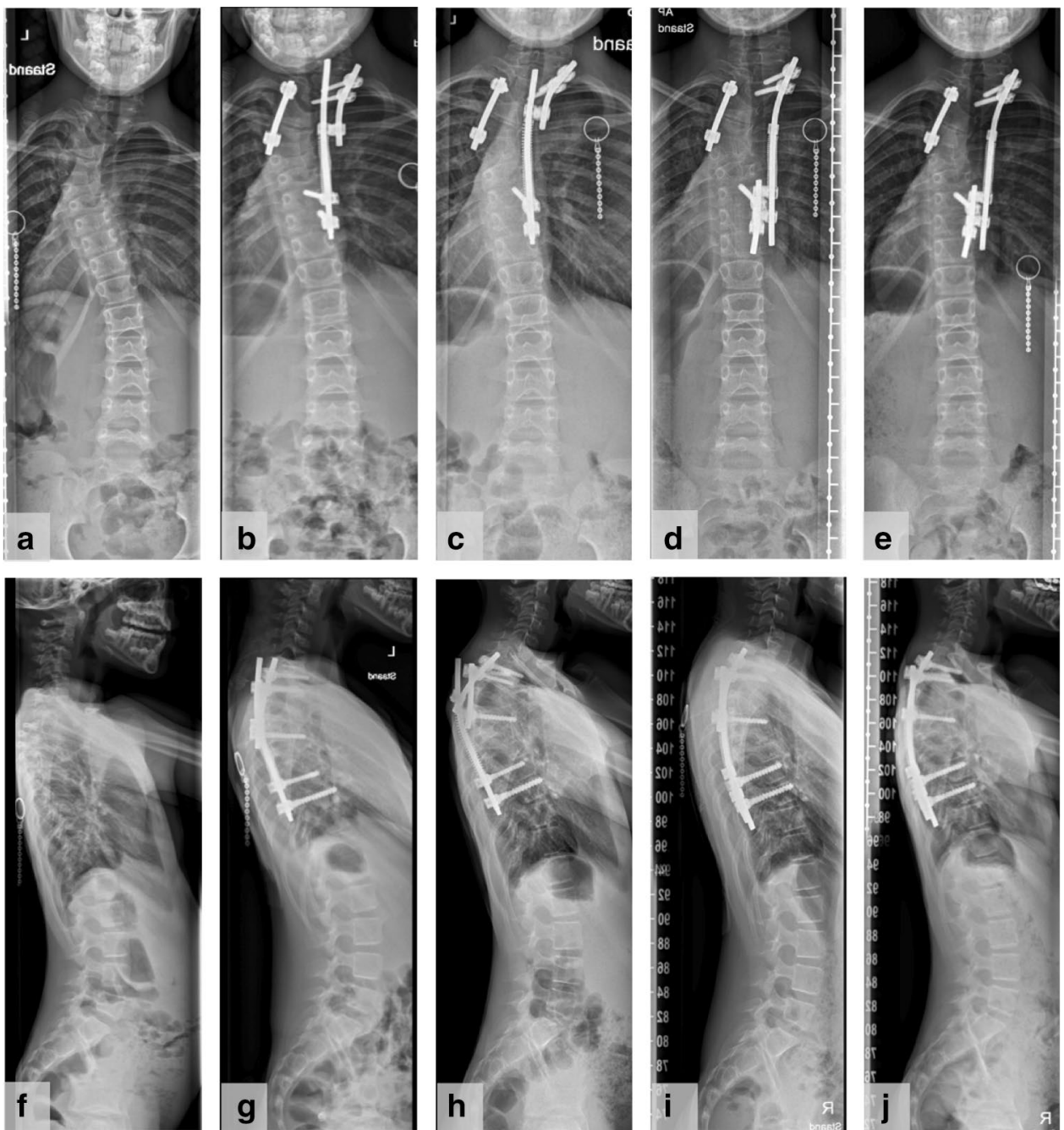

Degree of scoliosis after implantation

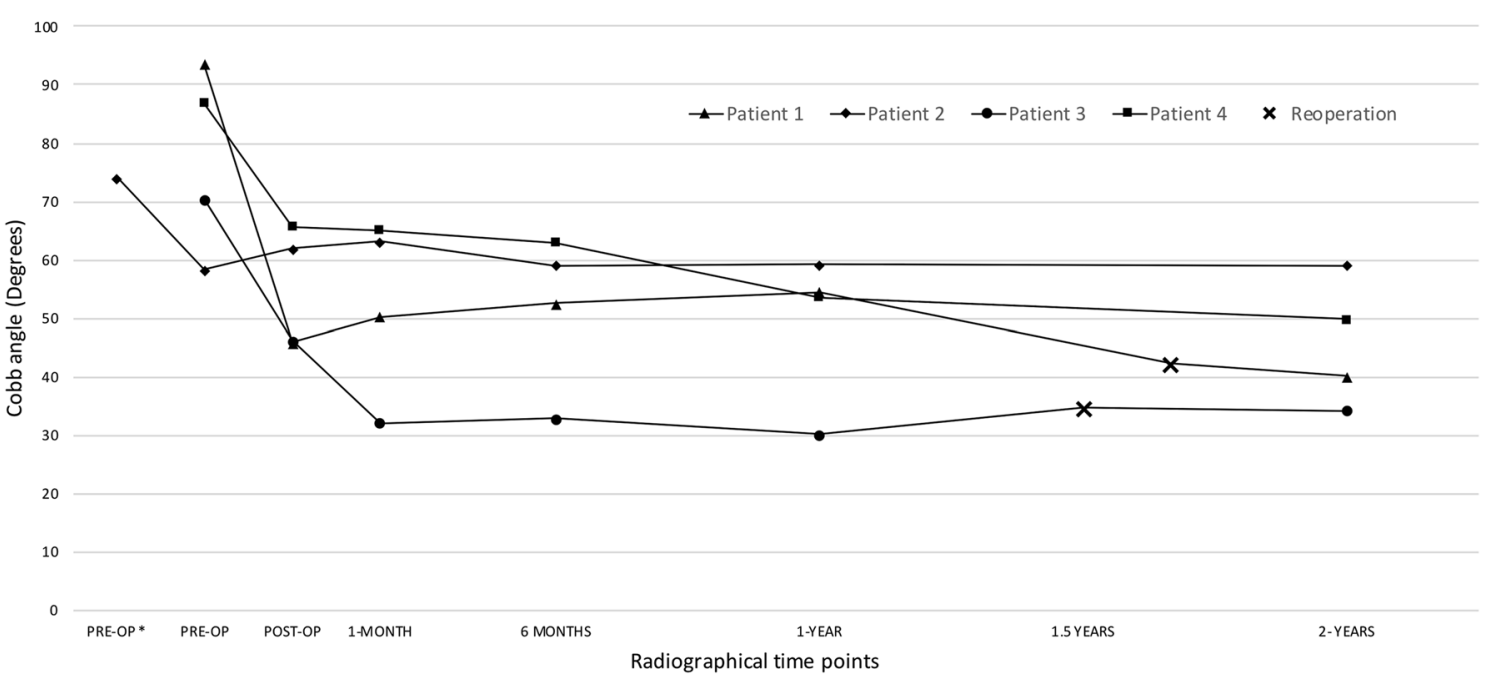

Fig. 6 Cobb angle measured in degrees on serial x-rays. Pre-op* indicates the pre-operative $\mathrm{x}$-ray before initial growth system implantation. Pre-op indicates the pre-operative $x$-ray before initial growth system implantation. Post-op indicates the post-operative $\mathrm{x}$-ray directly after SDS implantation. The $\mathrm{X}$ indicates reoperation points at which the spring was re-tensioned 
Table 1 Major curve, kyphosis, T1-T12 height and T1-S1 height per patient

\begin{tabular}{|c|c|c|c|c|}
\hline & Pre-op ${ }^{1}$ & Post-op ${ }^{2}$ & 2-year FU $\mathrm{FU}^{3}$ & Latest $\mathrm{FU}^{4}$ \\
\hline \multicolumn{5}{|c|}{$\begin{array}{l}\text { Coronal major } \\
\text { curve }\end{array}$} \\
\hline Patient 1 & $84^{\circ}$ & $43^{\circ}$ & $49^{\circ}$ & $54^{\circ}$ \\
\hline Patient 2 & $57^{\circ}$ & $58^{\circ}$ & $60^{\circ}$ & $59^{\circ}$ \\
\hline Patient 3 & $87^{\circ}$ & $66^{\circ}$ & $50^{\circ}$ & $50^{\circ}$ \\
\hline Patient 4 & $70^{\circ}$ & $46^{\circ}$ & $34^{\circ}$ & $34^{\circ}$ \\
\hline \multicolumn{5}{|c|}{$\begin{array}{l}\text { Sagittal Kypho- } \\
\text { sis }\end{array}$} \\
\hline Patient 1 & $\begin{array}{l}-43^{\circ} \text { (Lordo- } \\
\text { sis) }\end{array}$ & $0.1^{\circ}$ & $46^{\circ}$ & $43^{\circ}$ \\
\hline Patient 2 & $\begin{array}{l}-20^{\circ} \text { (Lordo- } \\
\text { sis) }\end{array}$ & $3^{\circ}$ & $20^{\circ}$ & $21^{\circ}$ \\
\hline Patient 3 & $28^{\circ}$ & $29^{\circ}$ & $38^{\circ}$ & $38^{\circ}$ \\
\hline Patient 4 & $14^{\circ}$ & $21^{\circ}$ & $38^{\circ}$ & $38^{\circ}$ \\
\hline \multicolumn{5}{|c|}{ T1-T12 height } \\
\hline Patient 1 & $111 \mathrm{~mm}$ & 125 & $134 \mathrm{~mm}$ & $137 \mathrm{~mm}$ \\
\hline Patient 2 & $149 \mathrm{~mm}$ & 146 & $160 \mathrm{~mm}$ & $163 \mathrm{~mm}$ \\
\hline Patient 3 & $109 \mathrm{~mm}$ & 141 & $162 \mathrm{~mm}$ & $162 \mathrm{~mm}$ \\
\hline Patient 4 & $152 \mathrm{~mm}$ & 151 & $170 \mathrm{~mm}$ & $170 \mathrm{~mm}$ \\
\hline \multicolumn{5}{|c|}{ T1-S1 height } \\
\hline Patient 1 & $174 \mathrm{~mm}$ & $233 \mathrm{~mm}$ & $251 \mathrm{~mm}$ & $254 \mathrm{~mm}$ \\
\hline Patient 2 & $267 \mathrm{~mm}$ & $277 \mathrm{~mm}$ & $290 \mathrm{~mm}$ & $292 \mathrm{~mm}$ \\
\hline Patient 3 & $211 \mathrm{~mm}$ & $244 \mathrm{~mm}$ & $285 \mathrm{~mm}$ & $285 \mathrm{~mm}$ \\
\hline Patient 4 & $268 \mathrm{~mm}$ & $272 \mathrm{~mm}$ & $305 \mathrm{~mm}$ & $305 \mathrm{~mm}$ \\
\hline
\end{tabular}

${ }^{1}$ Pre-op indicates the pre-operative X-ray before SDS implantation

${ }^{2}$ Post-op indicates the post-operative $\mathrm{X}$-ray directly after SDS implantation

${ }^{3}$ 2-year FU indicates X-ray at 2-year follow-up

${ }^{4}$ Latest FU indicates the last available X-ray at the time of latest follow-up

${ }^{5}$ Negative numbers indicate a lordosis and positive numbers a kyphosis

The overall T1-S1 height increase that occurred after index surgery was $1.3 \mathrm{~cm} /$ year in the first 2 years. The T1-T12 height increased $0.8 \mathrm{~cm} /$ year (Table2). The T1-S1 Freehand T1-S1 length growth in the coronal plane was $1.5 \mathrm{~cm} /$ year and $1.6 \mathrm{~cm} /$ year in the sagittal plane. The spring distraction was $1.1 \mathrm{~cm} /$ year (Fig. 7).

\section{Reoperations and complications}

Due to successful elongation, we decided to re-tension the springs in the first SCT patient after 19 months when $1.6 \mathrm{~cm}$ of spring distraction had been gained. As expected, there was some wear debris present around the parallel connector. Histological analysis showed foreign body reaction (macrophages) without inflammation, consistent with the bioinert nature of Titanium debris. In the second cervicothoracic scoliosis patient protrusion of the rod caused skin problems 19 months after implantation that required implant exchange. During the revision, the spring was changed and re-tensioned. Again, metal debris was observed without inflammation, the scar tissue that encapsulated the spring did not prevent it to expand. There were no deep infections, rod fractures, spring fractures or screw pull-outs in all 4 patients.

\section{Discussion}

This case series has shown that the feasibility of the spring distraction system (SDS) as a relatively easy and low invasive option for complex congenital deformities. In addition to maintaining correction and spinal growth, the SDS has shown the unique potential to further correct these rigid deformities after implantation, especially in the sagittal plane. The SDS was developed because we felt there were no other systems that could halt the progressive and lifethreatening lordosis of the congenitally posteriorly fused spine in SCT syndrome. Although we performed posterior osteotomies, we expected that the available growth-friendly systems, even with the shortest possible distraction intervals, would have resulted in a rigid recurrence of bony fusion over a short period of time. In these cases, a continuous distraction force was needed that no other existing system could provide. There is only one case report that showed spinal deformity reduction after initial surgery using daily distractions with an MCGR. However, the MCGR was implanted without initial correction and was applied more like preoperative halo gravity traction for a limited time [23].

Our system is easy to contour in both the coronal and the sagittal plane unlike for instance the MCGR. Furthermore, the SDS is relatively mobile due to the sliding connections at the proximal anchors. Theoretically, a more dynamic system is less vulnerable to fatigue failures as compared to static rods as demonstrated with finite element models [16]. [24] Although wear debris is a serious concern, we saw no abundant debris nor did we observe adverse tissue reactions.

We realize that the use of a new device with active distraction is not without risks. Therefore, both the development and a thorough risk analysis of the distraction spring and components were done together with the engineers from the University of Twente (the Netherlands) and our department of medical technology and clinical physics (UMC Utrecht, the Netherlands). Having a department with a medical device certification (ISO 13,485) inside the academic hospitals allows us to develop, manufacture and use hospital-specific medical devices for clinical research, which is especially important because of the upcoming Medical Device Regulation (MDR) laws in the European Union. We first looked at the forces delivered with the MCGR and 
Table 2 Coronal and sagittal parameters $($ Mean $\pm \mathrm{SD})$

\begin{tabular}{lllll}
\hline & Pre-op $^{1}$ & Post-op $^{2}$ & 2-year FU & Latest FU $^{3}$ \\
\hline Coronal & & & & \\
Major Curve & $74^{\circ}( \pm 14)$ & $53^{\circ}( \pm 10)$ & $48^{\circ}( \pm 10)$ & $49^{\circ}( \pm 11)$ \\
Minor Curve & $45^{\circ}( \pm 20)$ & $27^{\circ}( \pm 16)$ & $25^{\circ}( \pm 16)$ & $23^{\circ}( \pm 15)$ \\
Pelvic obliquity & $9^{\circ}( \pm 9)$ & $5^{\circ}( \pm 2)$ & $4^{\circ}( \pm 3)$ & $5^{\circ}( \pm 2)$ \\
Coronal balance & $25 \mathrm{~mm}( \pm 18)$ & $16 \mathrm{~mm}( \pm 9)$ & $9 \mathrm{~mm}( \pm 7)$ & $11 \mathrm{~mm}( \pm 7)$ \\
Apical vertebral translation & $45 \mathrm{~mm}( \pm 16)$ & $22 \mathrm{~mm}( \pm 19)$ & $16 \mathrm{~mm}( \pm 12)$ & $15 \mathrm{~mm}( \pm 10)$ \\
Sagittal & & & & \\
Kyphosis (T4-T12) & $-6^{\circ}( \pm 32)$ & $13^{\circ}( \pm 14)$ & $36^{\circ}( \pm 11)$ & $35^{\circ}( \pm 10)$ \\
Lordosis (L1-L5) & $41^{\circ}( \pm 9)$ & $53^{\circ}( \pm 21)$ & $45^{\circ}( \pm 24)$ & $34^{\circ}( \pm 8)$ \\
Pelvic Tilt & $5^{\circ}( \pm 8)$ & $10^{\circ}( \pm 9)$ & $6^{\circ}( \pm 7)$ & $5^{\circ}( \pm 8)$ \\
Sagittal vertical axis (SVA) & $17 \mathrm{~mm}( \pm 8)$ & $13 \mathrm{~mm}( \pm 38)$ & $22 \mathrm{~mm}( \pm 14)$ & $14 \mathrm{~mm}( \pm 17)$ \\
\hline
\end{tabular}

${ }^{1}$ Pre-op indicates the pre-operative X-ray before SDS implantation

${ }^{2}$ Post-op indicates the post-operative X-ray directly after SDS implantation

${ }^{3}$ 2-year FU indicates X-ray at 2-year follow-up

${ }^{4}$ Latest FU indicates the last available X-ray at the time of latest follow-up

${ }^{5}$ Negative numbers indicate a lordosis and positive numbers a kyphosis
Table 3 Spinal growth $($ Mean \pm SD)

\begin{tabular}{ll}
\hline & Post-op'-2-year FU \\
\hline T1-T12 height & $0.8 \mathrm{~cm} /$ year $( \pm 0.3)$ \\
T1-S1 height & $1.3 \mathrm{~cm} /$ year $( \pm 0.6)$ \\
T1-S1 freehand coronal & $1.5 \mathrm{~cm} /$ year $( \pm 0.3)$ \\
T1-S1 freehand sagittal & $1.6 \mathrm{~cm} /$ year $( \pm 0.4)$ \\
Spring distraction $^{3}$ & $1.1 \mathrm{~cm} /$ year $( \pm 0.3)$ \\
\hline
\end{tabular}

${ }^{1}$ Post-op indicates X-ray directly after SDS implantation

${ }^{2}$ 2-year FU indicates X-ray at 2-year follow-up

${ }^{3}$ Spring distraction is the growth in spring length in $\mathrm{cm}$ between postop and 2-year follow-up traditional growing rods. The maximal distraction force of a single MCGR rod is $270 \mathrm{~N}$ and for a single standard traditional growing rod it may easily exceed $500 \mathrm{~N}$ [14-16]. When used as bilateral systems, these forces are doubled. However, these forces are applied as peak loads periodically and not continuously. In an attempt to calculate the optimal continuous force, we found a force between 25 and $150 \mathrm{~N}$ to be sufficient to gain $10 \mathrm{~mm}$ in a year. This was confirmed with finite element models of Agarwal et al. and Abolaeha et al. $[12,13]$ Due to loss of force with distraction of the springs, we decided to develop a spring with a maximal force of $75 \mathrm{~N}$ that could be used bilaterally to deliver a total maximal force of $150 \mathrm{~N}$. This spring was made from

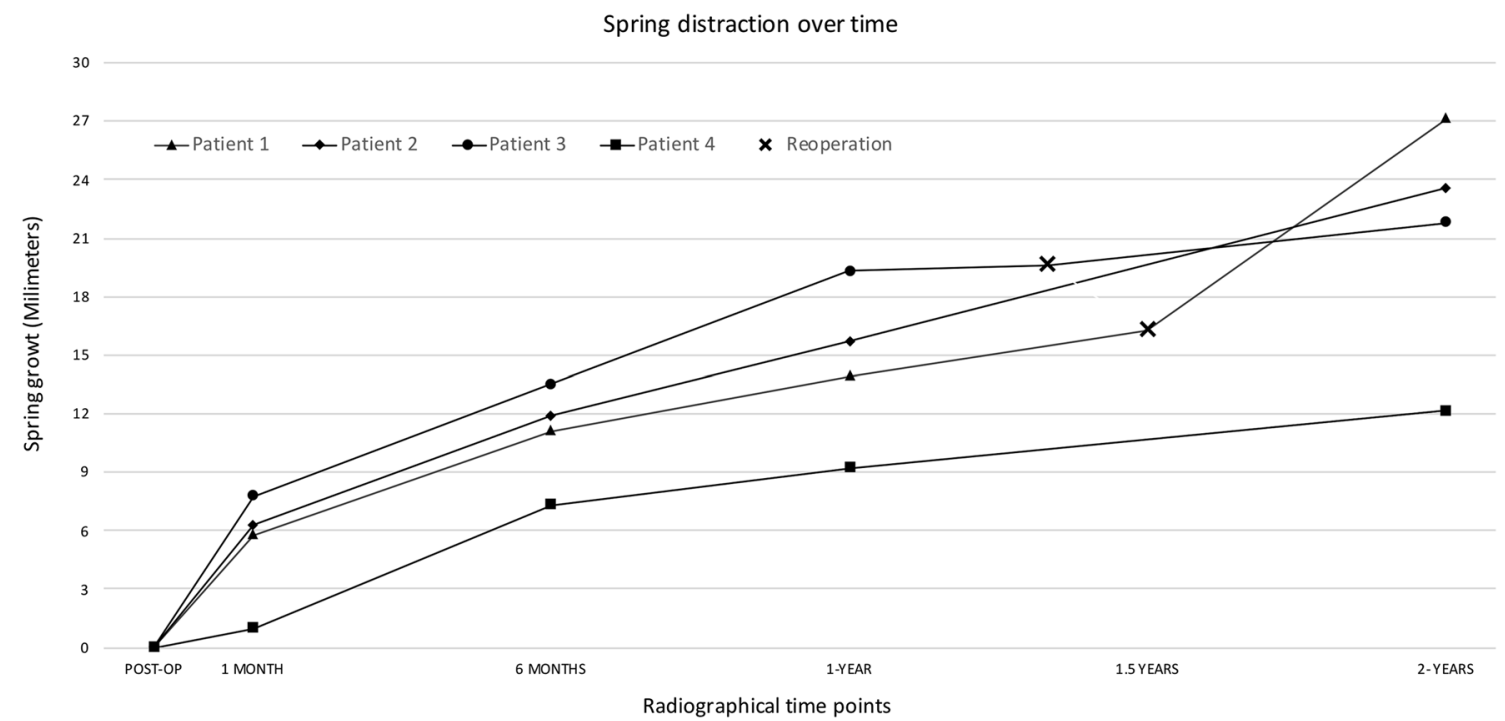

Fig. 7 Spring distraction measured on serial $\mathrm{x}$-rays. Post-op indicates the post-operative $\mathrm{x}$-ray directly after SDS implantation. The X indicates reoperation points at which the spring was re-tensioned 
medical grade titanium alloy to minimize adverse tissue reactions [25]. The spring dimensions were guided based on the anatomical limitations of the first patient' small size, desired ratio between compressed and expanded version of the spring, ability to fit around a standard spinal rod and available wire thickness of medical grade Ti-6Al-4 V.

Since we treated very rigid congenital deformities, the $38 \%$ major coronal curve correction and maintenance was at the lower range of the results reported in the literature of MCGR (32-58\% correction) [26-29]. Despite the rigidity of these patients, the correction improved over time and the T1-S1 spinal growth even approached natural growth during the same period [3].

Although the gradual and spontaneous correction obtained in all dimensions compares favorably with other systems, springs lose distraction force when they expand. This can be mitigated by using a longer spring for certain indications. Based on Hooke's law this will decrease the spring constant but not the maximal force [30]. Consequently, by using two springs in series the maximum force will be the same $(75 \mathrm{~N})$ but the length of travel doubles $(68 \mathrm{~mm})$. Therefore, after $2 \mathrm{~cm}$ growth, the single spring has a remaining force of about $25 \mathrm{~N}$ whereas the double spring still delivers $50 \mathrm{~N}$. Another concern may be overcorrection, especially in the sagittal plane despite the fact that many scoliotic deformities are longer anteriorly [31]. For the sliding anchors we used standard oversized connectors in an offlabel manner, they can be improved to slide better and cause less debris. We are currently designing better alternatives that also minimize frictional forces and von Mises stresses on the instrumentation.

\section{Limitations}

This study is only a prospective case series with a relatively short follow-up period and without a control group. The patients had very specific deformities which may not represent the majority of early onset deformity patients. Pulmonary function tests are not routinely performed at our institute and therefore we did not measure all patients. For the corrections that we observed after insertion of SDS, especially for the scoliosis cases, the individual effect of distraction and the hemi-epiphysiodesis could not be determined. Nevertheless, we believe that this limited data does show feasibility and proof of concept of the SDS, similarly as was shown for the first 2 magnetically controlled growing rod patients reported in 2012 [6]. To further study the possibilities and limitations, we have initiated a prospective clinical trial, where a broader range and less complex growing spine indications are included.

\section{Conclusion}

This is the first report of spring-based distraction to treat complex spinal deformities in the growing child. The early results of four patients show the potential of the innovative Spring Distraction System (SDS) to reduce the deformity and maintain growth after insertion, without additional lengthening procedures. Obviously, improvement of this inhouse developed device, its long-term results and research on broader applications are our next step.

Author contributions All authors contributed to the study conception and design. The data collection and analysis were performed by S.P.J. Wijdicks and J.V.C. Lemans. The first draft of the manuscript was written by S.P.J. Wijdicks and J.V.C. Lemans. All authors commented on previous versions of the manuscript and all authors read and approved the final manuscript.

Funding There was no financial support for this study.

Data availability All data collected or analyzed during this study are included in this published article.

\section{Complaince with ethical standards}

Conflict of interest Each author certifies that he or she has no commercial associations (eg, consultancies, stock ownership, equity interest, patent/licensing arrangements, etc.) that might pose a conflict of interest in connection with the submitted article.

Ethical approval For this study institutional ethical review board approval was obtained (METC nr. 16-276). The study was performed in accordance with the ethical standards in the 1964 Declaration of Helsinki and in accordance with relevant regulations. All details that might disclose the identity of the subjects under study are omitted.

Open Access This article is licensed under a Creative Commons Attribution 4.0 International License, which permits use, sharing, adaptation, distribution and reproduction in any medium or format, as long as you give appropriate credit to the original author(s) and the source, provide a link to the Creative Commons licence, and indicate if changes were made. The images or other third party material in this article are included in the article's Creative Commons licence, unless indicated otherwise in a credit line to the material. If material is not included in the article's Creative Commons licence and your intended use is not permitted by statutory regulation or exceeds the permitted use, you will need to obtain permission directly from the copyright holder. To view a copy of this licence, visit http://creativecommons.org/licenses/by/4.0/.

\section{References}

1. Campbell RM Jr, Smith MD (2007) Thoracic insufficiency syndrome and exotic scoliosis. J Bone Joint Surg Am 89(Suppl 1):108-122. https://doi.org/10.2106/JBJS.F.00270

2. Akbarnia BA, Marks DS, Boachie-Adjei O, Thompson AG, Asher MA (2005) Dual growing rod technique for the treatment 
of progressive early-onset scoliosis: a multicenter study. Spine 30:S46-57. https://doi.org/10.1097/01.brs.0000175190.08134.73

3. Wijdicks SPJ, Tromp IN, Yazici M, Kempen DHR, Castelein RM, Kruyt MC (2019) A comparison of growth among growth-friendly systems for scoliosis: a systematic review. Spine J 19:789-799. https://doi.org/10.1016/j.spinee.2018.08.017

4. Luque ER (1982) Paralytic scoliosis in growing children. Clin Orthop Relat Res. https://doi.org/10.1097/00003086-19820 3000-00030

5. McCarthy RE, Luhmann S, Lenke L, McCullough FL (2014) The Shilla growth guidance technique for early-onset spinal deformities at 2-year follow-up: a preliminary report. J Pediatr Orthop 34:1-7. https://doi.org/10.1097/BPO.0b013e31829f92dc

6. Cheung KM, Cheung JP, Samartzis D, Mak KC, Wong YW, Cheung WY, Akbarnia BA, Luk KD (2012) Magnetically controlled growing rods for severe spinal curvature in young children: a prospective case series. Lancet 379:1967-1974. https:// doi.org/10.1016/S0140-6736(12)60112-3

7. Chorney JM, Kain ZN (2009) Behavioral analysis of children's response to induction of anesthesia. Anesth Analg 109:1434 1440. https://doi.org/10.1213/ane.0b013e3181b412cf

8. Matsumoto H, Williams BA, Corona J, Comer JS, Fisher PW, Neria Y, Roye BD, Roye DP, Vitale MG (2014) Psychosocial effects of repetitive surgeries in children with early-onset scoliosis: are we putting them at risk? J Pediatr Orthop 34:172-178. https://doi.org/10.1097/BPO.0b013e3182a11d73

9. Reichel D, Schanz J (2003) Developmental psychological aspects of scoliosis treatment. Pediatr Rehabil 6:221-225. https://doi. org/10.1080/13638490310001644593

10. Bess S, Akbarnia BA, Thompson GH, Sponseller PD, Shah SA, El Sebaie H, Boachie-Adjei O, Karlin LI, Canale S, Poe-Kochert C, Skaggs DL (2010) Complications of growing-rod treatment for early-onset scoliosis: analysis of one hundred and forty patients. J Bone Joint Surg Am 92:2533-2543. https://doi.org/10.2106/ JBJS.I.01471

11. Cahill PJ, Marvil S, Cuddihy L, Schutt C, Idema J, Clements DH, Antonacci MD, Asghar J, Samdani AF, Betz RR (2010) Autofusion in the immature spine treated with growing rods. Spine 35:E1199-1203. https://doi.org/10.1097/BRS.0b013e3181e21b50

12. Abolaeha OA, Weber J, Ross LT (2012) Finite element simulation of a scoliotic spine with periodic adjustments of an attached growing rod. Conf Proc IEEE Eng Med Biol Soc 2012:5781-5785. https://doi.org/10.1109/EMBC.2012.6347308

13. Agarwal A, Zakeri A, Agarwal AK, Jayaswal A, Goel VK (2015) Distraction magnitude and frequency affects the outcome in juvenile idiopathic patients with growth rods: finite element study using a representative scoliotic spine model. Spine J 15:18481855. https://doi.org/10.1016/j.spinee.2015.04.003

14. Noordeen HM, Shah SA, Elsebaie HB, Garrido E, Farooq N, Al-Mukhtar M (2011) In vivo distraction force and length measurements of growing rods: which factors influence the ability to lengthen? Spine 36:2299-2303. https://doi.org/10.1097/ BRS.0b013e31821b8e16

15. Rolton D, Thakar C, Wilson-MacDonald J, Nnadi C (2016) Radiological and clinical assessment of the distraction achieved with remotely expandable growing rods in early onset scoliosis. Eur Spine J 25:3371-3376. https://doi.org/10.1007/s0058 6-015-4223-4

16. Teli M, Grava G, Solomon V, Andreoletti G, Grismondi E, Meswania J (2012) Measurement of forces generated during distraction of growing-rods in early onset scoliosis. World J Orthop 3:15-19. https://doi.org/10.5312/wjo.v3.i2.15

17. Waugh TR (1966) Intravital measurements during instrumental correction of idiopathic scoliosis. Acta Orthop Scand. https://doi. org/10.3109/ort.1966.37.suppl-93.01

18. Agarwal A, Goswami A, Vijayaraghavan GP, Srivastava A, Kandwal P, Nagaraja UB, Goel VK, Agarwal AK, Jayaswal A (2019)
Quantitative characteristics of consecutive lengthening episodes in early-onset scoliosis (EOS) patients with dual growth rods. Spine 44:397-403. https://doi.org/10.1097/BRS.0000000000 002835

19. Ouyang J, Zhu Q, Zhao W, Xu Y, Chen W, Zhong S (2005) Biomechanical assessment of the pediatric cervical spine under bending and tensile loading. Spine 30:E716-723. https://doi. org/10.1097/01.brs.0000192280.53831.70

20. Luck JF, Nightingale RW, Song Y, Kait JR, Loyd AM, Myers BS, Bass CR (2013) Tensile failure properties of the perinatal, neonatal, and pediatric cadaveric cervical spine. Spine 38:E1-12. https://doi.org/10.1097/BRS.0b013e3182793873

21. Nuckley DJ, Linders DR, Ching RP (2013) Developmental biomechanics of the human cervical spine. J Biomech 46:1147-1154. https://doi.org/10.1016/j.jbiomech.2013.01.005

22. Dong L, Li G, Mao H, Marek S, Yang KH (2013) Development and validation of a 10-year-old child ligamentous cervical spine finite element model. Ann Biomed Eng 41:2538-2552. https://doi. org/10.1007/s10439-013-0858-7

23. Cheung JP, Samartzis D, Cheung KM (2014) A novel approach to gradual correction of severe spinal deformity in a pediatric patient using the magnetically-controlled growing rod. Spine J 14:e7-13. https://doi.org/10.1016/j.spinee.2014.01.046

24. Lemans J, Kodigudla M, Kelkar A, Kruyt M, Goel V, Agarwal A (2018) Spring distraction system for early onset scoliosis provides continuous distraction without a potential increase in rod fractures, compared to traditional growing rods. Spine Deform 6:819-820

25. Brunette DM (2001) Titanium in medicine : material science, surface science, engineering, biological responses, and medical applications. Springer, Berlin

26. Akbarnia BA, Pawelek JB, Cheung KM, Demirkiran G, Elsebaie H, Emans JB, Johnston CE, Mundis GM, Noordeen H, Skaggs DL, Sponseller PD, Thompson GH, Yaszay B, Yazici M (2014) Traditional growing rods versus magnetically controlled growing rods for the surgical treatment of early-onset scoliosis: a casematched 2-year study. Spine Deform 2:493-497. https://doi. org/10.1016/j.jspd.2014.09.050

27. Dannawi Z, Altaf F, Harshavardhana NS, El Sebaie H, Noordeen H (2013) Early results of a remotely-operated magnetic growth rod in early-onset scoliosis. Bone Jt. https://doi. org/10.1302/0301-620X.95B1.29565

28. Hickey BA, Towriss C, Baxter G, Yasso S, James S, Jones A, Howes J, Davies P, Ahuja S (2014) Early experience of MAGEC magnetic growing rods in the treatment of early onset scoliosis. Eur Spine J 23(Suppl 1):S61-65. https://doi.org/10.1007/s0058 6-013-3163-0

29. Hosseini P, Pawelek J, Mundis GM, Yaszay B, Ferguson J, Helenius I, Cheung KM, Demirkiran G, Alanay A, Senkoylu A, Elsebaie H, Akbarnia BA (2016) Magnetically controlled growing rods for early-onset scoliosis: a multicenter study of 23 cases with minimum 2 years follow-up. Spine 41:1456-1462. https:// doi.org/10.1097/BRS.0000000000001561

30. Ugural AC, Fenster SK (1995) Advanced strength and applied elasticity. Prentice Hall, Upper Saddle River, N.J.

31. Brink RC, Schlosser TPC, Colo D, Vavruch L, van Stralen M, Vincken KL, Malmqvist M, Kruyt MC, Tropp H, Castelein RM (2017) Anterior spinal overgrowth is the result of the scoliotic mechanism and is located in the disc. Spine 42:818-822. https:// doi.org/10.1097/BRS.0000000000001919

Publisher's Note Springer Nature remains neutral with regard to jurisdictional claims in published maps and institutional affiliations. 